\title{
STUNTING AMONG CHILDREN OF 18 TO 36 MONTHS OF AGE IN BHAWALGHAR VILLAGE, DISTRICT LODHRAN: A CROSS-SECTIONAL STUDY
}

\author{
Haider Ali Younas ${ }^{1}$, Siham Sikander², Mudassar Mushtaq Jawad Abbasi ${ }^{3}$ \\ ${ }^{1}$ Public Health Fellow, Health Services Academy, Islamabad. \\ ${ }^{2}$ Director of Research, Human Development Research Foundation Islamabad. \\ ${ }^{3}$ Assistant Professor, Health Services Academy, Islamabad. \\ Correspondence: HaiderAli Younas.Email: haideraliyounas@hsa.edu.pk
}

\begin{abstract}
Background: Stunting is chronic restriction of growth in height indicated by low height-for-age. It is a reliable indicator of long-term under nutrition among young children. Stunted children are more prone to communicable diseases. The main causes of stunting are not providing proper nutritious food, not enough food and of poor quality, improper feeding practices and different infections including malaria, ARI and diarrhea. We conducted this survey to determine the frequency and determinants of stunting among 18 to 36 months old children in Bhawalghar Village, District Lodhran

Methods: We did cross-sectional study in Bhawalghar village of district Lodhran. All of the children from 18 to 36 months of age were included in this study from two randomly selected clusters.

Results: Gender, parental education, income, type of housing, vaccination coverage, parity of women, height of child and number of food items were identified as determinants of stunting. There was a statistically significant relationship between stunting and the study variables. We found that about half $(48 \%)$ of the children of age 18-36 months living in Bhawalghar Village, District Lodhran were stunted.

Conclusions: Stunting is a major problem among the children of rural Punjab, Pakistan. There is a dire need to improve the nutritional status of the children in this region.

Keywords: Stunting, nutrition, rural community, developing country
\end{abstract}

Introduction: Stunting is chronic restriction of growth in height indicated by low height-for-age. It is a reliable indicator of long-term under nutrition among young children. Good cumulative measure of "well being" for populations of children (because not affected by weight recovery). The main causes of stunting are not providing proper nutritious food, not enough food and of poor quality, . Improper feeding practices and different infections, including malaria, ARI and diarrhea (3), (4)

Timing: Age of onset varies, but usually in first 2-3 years of life. First few months, infants in developing countries grow just as quickly as children in reference populations (developed countries like Japan, Norway, and Germany etc.). Growth retardation starts from 2-6 month of life (often associated with weaning). Infants at risk during this time because of high nutritional requirements and high rates of infections (breast fed infants often protected) (5), (6).

Stunting undermines both physical and mental development with lifelong consequences (7), (8).

In 2012 globally, 162 million under-five year olds were stunted. $56 \%$ of all stunted children lived in Asia and $36 \%$ in Africa. The global trend in stunting prevalence and burden continues to decrease. Between 2000 and 2012 stunting prevalence declined from 33\% to $25 \%$ and the burden declined from 197 million to 162 million (9), (10).South-Asia bears 40\% global burden of child stunting (11).

In Pakistan in 1965 prevalence of stunting was $48 \%$. In 2012-13 prevalence of stunting was $45 \%$. Thus, not much change in more than 40 years. In 2012-13 stunting prevalence was (48\%) in Rural areas, $(37 \%)$ in Urban areas (12), (13).

Globally stunting reduced by continued investments in nutrition-specific interventions. Improved access to nutrition-sensitive approaches; primary health care networks, education, agriculture and social protection. (14), (15).

Methodology: A community based cross-sectional study was conducted in Bhawalghar Village, District Lodhran from 1st April to 30th June 2015. The Internal Review Board (IRB) of the Health Services Academy, Islamabad, granted ethical approval. Sample size of 104 was calculated onbasis of $45 \%$ prevalence of stunted children in Pakistan according to Pakistan Demographic and Health Survey 2012-13, with 95\% confidence interval, $10 \%$ of margin of error/degree of precision. All the children from 18 to 36 months of age were included in the study from two randomly 
selected clusters (localities) of Bhawalghar Village. Children with diagnosed congenital abnormalities and SAM (Kwashiorkor/Marasmus) were excluded from the study. Informed consent was obtained from mothers about feeding and food intake practices of the selected children through structured questionnaire, according to World Health Organization (WHO) standardized food intake questionnaire. Other questions were regarding social and demographic characteristics in relation with stunting. The nutritional status of children of 18 to 36 months old was measured anthropometrically. The height-for-age measurement status was, calculated shown in standard deviation (SD) units (Z-score) from the median of the reference population. Children with a measurement of $<-2$ SD units below the median of the reference population were considered short for their age (moderately stunted) and children with measurement of $<-3$ SD units below the median was considered to be severely stunted.

Results: Bhawalghar Village comprises of four Mohallas. Each Mohalla was a cluster and total cluster were four. Two clusters were randomly selected using the lottery method. All of the children from eighteen months to thirty six months (three years) of age were included in the study. Children with diagnosed congenital abnormalities and SAM (Kwashiorkor/Marasmus) were excluded from the study.Boys and girls percentages were $53 \%$ and $47 \%$ respectively. $50 \%$ fathers and $78 \%$ mothers were illiterate. $43 \%$ target population living in Pakka, $30 \%$ in Katcha-Pakka and $27 \%$ in Katcha houses. Majority of the women $(30.8 \%)$ mothers of $2,(29.8 \%)$ mothers of 3 and $(30.8 \%)$ mothers of 4 children. The vaccination coverage of their children is above $90 \%$ (Table-1).

Table 1: Descriptive analysis of SocioDemographics and Vaccination Coverage

\begin{tabular}{|l|l|c|c|}
\hline \multicolumn{2}{|c|}{ Variables } & Frequency (n) & Percentage (\%) \\
\hline \multirow{4}{*}{ Gender } & Boy & 55 & 53 \\
\cline { 2 - 4 } & Girl & 49 & 47 \\
\hline \multirow{4}{*}{ Father's Education } & Illiterate & 52 & 50 \\
\cline { 2 - 4 } & Primary & 20 & 19.2 \\
\cline { 2 - 4 } & Middle & 11 & 10.6 \\
\cline { 2 - 4 } & Higher & 21 & 20.2 \\
\hline \multirow{5}{*}{} & Illiterate & 81 & 77.9 \\
\cline { 2 - 4 } & Primary & 12 & 11.5 \\
\cline { 2 - 4 } & Middle & 4 & 3.8 \\
\hline
\end{tabular}

\begin{tabular}{|l|l|c|c|}
\hline \multicolumn{2}{|c|}{ Variables } & Frequency (n) & Percentage (\%) \\
\hline Mother's Education & Higher & 7 & 6.7 \\
\hline \multirow{4}{*}{ Type of House } & Pakka & 45 & 43.3 \\
\cline { 2 - 4 } & Katcha-Pakka & 31 & 29.8 \\
\cline { 2 - 4 } & Katcha & 28 & 26.9 \\
\hline \multirow{4}{*}{ Number of Children } & 1 & 9 & 8.7 \\
\cline { 2 - 4 } & 2 & 32 & 30.8 \\
\cline { 2 - 4 } & 3 & 31 & 29.8 \\
\cline { 2 - 4 } & 4 & 32 & 30.8 \\
\hline \multirow{3}{*}{ Vaccination Coverage } & Full & 94 & 90.4 \\
\cline { 2 - 4 } & Partial & 8 & 7.7 \\
\cline { 2 - 4 } & No Vaccination & 2 & 1.9 \\
\hline
\end{tabular}

According to World Health Organization (WHO) standardized food intake practices of children , $30 \%$ children consumed 4 food items in the last 24 hours(including day and night) $.46 \%$ consumed 5 or more food items.89\% children consumed Grains and Cereals. Majority of the children were consuming Roti.89\% consumed Dairy Products (especially milk). $52 \%$ consumed Vegetables. In Vegetables most were consuming Butter nut squash (gadu), Cabbage and Spinach. $77 \%$ children consumed Mixed Dish having 2 food items . Only $17 \%$ consumed Meat (white or red or both) and $11 \%$ fruits. Breast milk consumption was only $17 \%$ (Table-2).

Table 2: Food Items Consumed by Child in the last 24 Hours

\begin{tabular}{|l|c|c|c|}
\hline \multicolumn{2}{|c}{ Food Items } & $\begin{array}{c}\text { Frequency } \\
\text { (n) }\end{array}$ & $\begin{array}{c}\text { Percentage } \\
(\%)\end{array}$ \\
\hline \multirow{3}{*}{ Number of Food Items } & 2 & 6 & 5.8 \\
\cline { 2 - 4 } & 3 & 19 & 18.3 \\
\cline { 2 - 4 } & 4 & 31 & 29.8 \\
\cline { 2 - 4 } & 5 or more & 48 & 46.2 \\
\hline \multirow{2}{*}{ Grains and Cereals } & Yes & 93 & 89.4 \\
\cline { 2 - 4 } & No & 11 & 10.6 \\
\hline \multirow{2}{*}{ Vegetables } & Yes & 54 & 51.9 \\
\cline { 2 - 4 } & No & 50 & 48.1 \\
\hline \multirow{2}{*}{ Fruits } & Yes & 11 & 10.6 \\
\cline { 2 - 4 } & No & 93 & 89.4 \\
\hline \multirow{2}{*}{ Meat (white or red or both) } & Yes & 18 & 17.3 \\
\cline { 2 - 4 } & No & 86 & 82.7 \\
\hline \multirow{2}{*}{ Dairy Products (especially milk) } & Yes & 93 & 89.4 \\
\cline { 2 - 4 } & No & 11 & 10.6 \\
\hline \multirow{2}{*}{ Breast Milk } & Yes & 17 & 16.3 \\
\cline { 2 - 4 } & No & 87 & 83.7 \\
\hline \multirow{2}{*}{ Oil and Ghee } & Yes & 65 & 62.5 \\
\cline { 2 - 4 } & No & 39 & 37.5 \\
\hline \multirow{2}{*}{ Other Foods } & Yes & 91 & 87.5 \\
\hline \multirow{2}{*}{ Mixed Dish } & No & 13 & 12.5 \\
\hline \multirow{2}{*}{ How many times Yesterday did } & Yes & 80 & 77 \\
\cline { 2 - 4 } Food Lonsume any Item from & No & 24 & 23 \\
\cline { 2 - 4 } & Once & 14 & 13.5 \\
\cline { 2 - 4 } & Twice & 57 & 54.8 \\
\cline { 2 - 4 } & 4 times or & 1 & 30.8 \\
\hline & & & \\
\hline
\end{tabular}

The stunting of children was analyzed by $Z$ score according to $\mathrm{WHO}$ guide lines. Those children having $Z$ score < -2 SD were considered short for their age (Stunted). Children having Z score < -3 SD were considered severely stunted. Majority of the children, 54 children (52\%) were normal, where as $34(33 \%)$ were moderately stunted and $16(15 \%)$ were severely stunted. Stunting was higher in girls as compare to boys, $19(39 \%)$ girls moderately stunted and $9(18 \%)$ severely stunted. $15(27 \%)$ boys were moderately stunted and $7(13 \%)$ were severely stunted. As age groups continue to increase, normal children continue to decrease; moderately and severely stunted children continue to increase (figure-1). 
Figure 1: Multiple bar chart of Gender and Age and their Z-Score

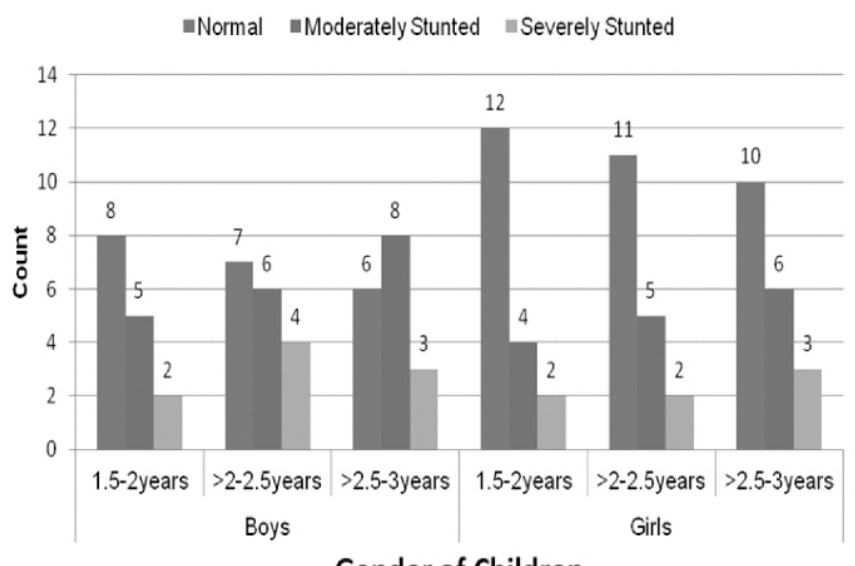

Gender of Children

For the categorical variables, chi-square applied to see the association between study variables and Stunting. Frequency of Stunting was higher in girls than boys. Illiterate parents had highest frequency of Stunted Children. Parents Education Matriculation or above had lowest frequency of Stunted Children. Numbers of Stunted Children were more in Katcha and Katcha-Pakka houses than Normal Children. On the other hand in Pakka houses number of Normal Children was much higher than Stunted Children. Increasing parity linked to increase stunting. Results are strongly statistically significant. This means that socio-demographic characteristics highly influence the height for age (stunting) of children Table-3)

Table 3: Association of categorical variables with Z-score of nutritional status

\begin{tabular}{|c|c|c|c|c|c|}
\hline \multicolumn{2}{|c|}{ Variables } & $\begin{array}{l}\text { Normal } \\
\text { Children }\end{array}$ & $\begin{array}{c}\text { Moderately } \\
\text { Stunted } \\
(<-2)\end{array}$ & $\begin{array}{c}\text { Severely } \\
\text { Stunted } \\
(<-3)\end{array}$ & $\begin{array}{r}P- \\
\text { Value } \\
(< \\
0.05)\end{array}$ \\
\hline \multirow{2}{*}{$\begin{array}{c}\text { Gender } \\
\text { ofChildren }\end{array}$} & Boys & 21 & 19 & 9 & \multirow[t]{2}{*}{0.000} \\
\hline & Girls & 33 & 15 & 7 & \\
\hline \multirow{4}{*}{$\begin{array}{l}\text { Father's } \\
\text { Education }\end{array}$} & Illiterate & 20 & 17 & 10 & \multirow{4}{*}{0.002} \\
\hline & Primary & 10 & 8 & 4 & \\
\hline & Middle & 10 & 4 & 1 & \\
\hline & Higher & 14 & 5 & 1 & \\
\hline \multirow{4}{*}{$\begin{array}{l}\text { Mother's } \\
\text { Education }\end{array}$} & Illiterate & 36 & 27 & 14 & \multirow{4}{*}{0.000} \\
\hline & Primary & 10 & 4 & 2 & \\
\hline & Middle & 5 & 2 & 0 & \\
\hline & Higher & 3 & 1 & 0 & \\
\hline \multirow{3}{*}{$\begin{array}{l}\text { Type of } \\
\text { House }\end{array}$} & Pakka & 26 & 15 & 4 & \multirow{3}{*}{0.000} \\
\hline & $\begin{array}{l}\text { Katcha- } \\
\text { Pakka }\end{array}$ & 15 & 10 & 6 & \\
\hline & Katcha & 13 & 9 & 6 & \\
\hline \multirow{5}{*}{$\begin{array}{l}\text { Number of } \\
\text { children }\end{array}$} & 1 & 8 & 3 & 1 & \multirow{5}{*}{0.011} \\
\hline & 2 & 22 & 14 & 4 & \\
\hline & 3 & 16 & 11 & 6 & \\
\hline & 4 & 5 & 4 & 3 & \\
\hline & 5 or more & 3 & 2 & 2 & \\
\hline
\end{tabular}

Note: ${ }^{*}=$ significance level at $p<0.05$
Children taking two or three food items were mostly moderately or severely stunted. Majority of the children were consuming four or five food items. As number of food items consumption by children increases, moderately and severely stunting decreases subsequently. The chi square test was applied to test the association between number of food items and nutritional status (stunting). The result is statistically significant and association found between study variable and number of foods (Table4).

Table 4: Association between Number of food Items with nutritional Status

\begin{tabular}{|c|c|c|c|c|}
\hline \multirow{2}{*}{\multicolumn{2}{|c|}{ Variable (Food Items) }} & \multicolumn{2}{|c|}{ Nutritional Status } & \multirow[b]{2}{*}{ P-Value } \\
\hline & & \multirow{2}{*}{$\begin{array}{c}\text { Normal } \\
\text { Children (n) }\end{array}$} & \multirow{2}{*}{$\begin{array}{c}\begin{array}{c}\text { Stunted } \\
\text { Children (n) }\end{array} \\
7\end{array}$} & \\
\hline \multirow{6}{*}{$\begin{array}{l}\text { Number of } \\
\text { food items }\end{array}$} & 2 & & & \multirow{6}{*}{0.000} \\
\hline & 3 & 10 & 16 & \\
\hline & 4 & 16 & 12 & \\
\hline & 5 & 15 & 11 & \\
\hline & 6 & 8 & 4 & \\
\hline & 7 & 3 & 1 & \\
\hline
\end{tabular}

Note: ${ }^{*}=$ significance level at $p<0.05$

Discussion: The stunting of children was analyzed by $Z$ score according to WHO guidelines. Those children having $Z$ score $<-2$ SD were considered short for their age (moderately stunted). Children having $Z$ score < -3 SD were considered severely stunted.Frequency of stunting in the study area is $48 \%$; severe stunting is $15 \%$, it's an alarming figure. According to Pakistan National Nutritional Survey (NNS) 2011 prevalence of stunting in rural areas is $46.3 \%$ and severe stunting in rural areas is $24 \%$ (13). According to Pakistan Demographic and Health Survey (PDHS) 2012-13 prevalence of stunting in rural areas is $48 \%$ (5).Gender wise males were $53 \%$ and females $47 \%$. The frequency of moderate and severe stunting was higher in females as compared to males.lgnorance and negligence towards a female child in our society may be the cause of these results. (16). $50 \%$ fathers and $80 \%$ mothers were illiterate. Illiterate parents, especially mothers had the highest frequency of stunted children. Parental Education Matriculation or above had lowest frequency of Stunted Children. Malnutrition in children was lower for those whose mothers had a higher education status. (11). The monthly income of most $(72 \%)$ families was 6000-12000. This income group had highest frequency of stunted children $(34.6 \%)$. House hold income more than 15000 had lowest frequency of stunted children (3.8\%). Thus increasing income is associated with decreasing stunting. $57 \%$ people living in Katcha and Katcha-Pakka houses had the highest frequency ofmoderately and severely stunted children.Mothers having one child had lowest number of moderately and severely stunted children. As 
number of children of a mother increases the number of moderately and severely stunted children also increases gradually. Thus Increasing parity linked to increasing stunting. (15)The vaccination status of the children in study population showed that $90 \%$ of the children were fully vaccinated. This high rate had many reasons; major reason was that that these people were aware of the importance of vaccination, nearby health facility and vigilant lady health workers. The PDHS 2012-13 shows that vaccination coverage in rural areas is only $48 \%$ (5).Breast feeding was very common in the study area, with $92 \%$ of the children ever breastfed, very close to $94 \%$ children of Pakistan ever breast fed by PDHS 2012-13(5). 89\% children were consuming dairy products especially milk. Thus milk consumption was adequate.Grains and Cereals consumption was $89 \%$ which is satisfactory. Pulses consumption was less than $2 \%$. In comparison to rest of rural areas of Pakistan, pulses consumption was very low. Mainly because pulses were not grown in that area and people were mostly consuming those food items which were grown locally. Vegetables intake to an extent was satisfactory but fruits and meat intake was very low. The main reason of low intake of fruits and meat was poor socio-economic conditions. Children consuming 2 or 3 food items were mostly stunted. Children consuming 4 or 5 food items had a low frequency of moderately and severely stunted children. Thus the majority of the children were lacking balanced diet. A diet containing milk and other dairy products, grains and cereals, vegetables, fruits, meat (white or red or both), oil and ghee and pulses in sufficient quantity, quality and right proportion.

\section{Conclusion}

Stunting is a major public health issue of children. It is clear from the study that the frequency of stunting in the study population was $48 \%$. $48 \%$ stunting is an alarming figure. Gender, parental education, income, type of housing, parity of women, height of child and number of food items were identified as determinants of stunting. The association of stunting with parental education shows that the frequency of moderately and severely stunted children is high in children whose parents were illiterate. Increasing income was associated with decreasing stunting. There is a statistically significant relationship between stunting and different study variables.

\section{References}

1. Bhutta DZA. National Nutrition Survey Pakistan 2011; 56-8.

2. UNICEF."Progress For Children: A Report Card On Nutrition".

3. Organization World Health. Essential Nutrition Actions: improving maternal, newborn, infant and young child health and nutrition. 2013.

4. Interactions of: Malnutrition, Water Sanitation and Hygiene, Infections. Version 2005.
5. NIPS. Pakistan Demographic and Health Survey 2012-2013. National Institute of Population Studies.2013.

6. UNICEF.Improving child nutrition the achievable imperative for global progress, 2013.

7. CaulifieldLE, Richard SA, Rivera JA,MusgroveP,Black RE. Disease Control Priorities in Developing Countries.Washington (DC). World Bank; 2011.

8. Hunt J. ed. Investing in Child Nutrition in Asia. Asian Development Bank, 2000.

9. CaulifieldLE,Richard SA, Rivera JA, Musgrove $P$, Black RE. Disease Control Priorities in Developing Countries. Washington (DC). World Bank; 2011.

10. Black RE, Robert E, Cesar G, Victoria, Susan P, Walker et al. Maternal and child under nutrition and overweight in low-income and middleincome countries. The Lancet .2013;427-451.

11. UNICEF. Annual Report. 2011.

12. NIPS. Pakistan Demographic and Health Survey 2012-2013. National Institute of Population Studies.2013.

13. PMRC. Pakistan National Nutrition Survey 2011. Pakistan.

14. Kristof, Nicholas D. 2009; "The Hidden Hunger". New York Times.

15. World BANK: Scaling Up Nutrition :A framework for Action 2010.

16. Monika Blossner, Onis Md. Malnutrition Quatifying the health impact at national and local Levels. Environmental Burden of Disease. 2005. 